\title{
In-service Training as a Factor in the Formation of the Teacher's Individual Theory of Education
}

\author{
Dimitris P. Sakkoulis ${ }^{1}$, Anna Asimaki ${ }^{1}$ \& Dimitris K. Vergidis ${ }^{1}$ \\ ${ }^{1}$ Department of Primary Education, University of Patras, Patras, Greece \\ Correspondence: Dimitris P. Sakkoulis, University of Patras, Department of Primary Education, 170 Athinon Str, \\ 26442 Patras, Greece. Tel: 30-261-099-7380. E-mail: d.sakkoulis@upatras.gr
}

Received: October 16, 2017

doi:10.5539/ies.v11n3p48
Accepted: November 27, $2017 \quad$ Online Published: February 25, 2018

URL: https://doi.org/10.5539/ies.v11n3p48

\begin{abstract}
The purpose of this paper is the investigation of the prevailing forms of in-service training, the detection of the dominant pedagogical discourse they promote as well as their contribution to the shaping of the teacher's individual theory of education (I.T.E.). The research was conducted using semi-structured interviews with a sample of 11 teachers who work in schools in Patras and the data were analysed using B. Bernstein's theoretical framework. The results of the research revealed that in our case, the predominant form of in-service training is the lecture, while the scientific knowledge provided refers to the content and teaching of cognitive subjects, the diagnosis and handling of learning difficulties and the acquisition of skills in the use of teaching aids. It also became clear that the I.T.E. of the teachers who participated in the research is chiefly shaped by elements of the professional biography of each teacher, in which in-service training does not seem to hold a dominant position.
\end{abstract}

Keywords: individual theory of education, in-service training, pedagogic discourse, professional development

\section{Introduction}

In-service training, integrated within the framework of lifelong learning and the professional development of teachers, includes educational activities in which teachers participate - after completion of their initial studies which do not lead to a recognized study title. The activities compose an educational continuum which continuously interacts with the socio-economic, political and cultural environment that frames the educational system of the time. In-service training is characterised by its flexibility in space, time, content and teaching techniques (Vergidis, 1995 \& 2001; Sakkoulis, Assimaki, \& Vergidis, 2017a; Sakkoulis, Assimaki, \& Vergidis, 2017b). What's more, as an element of the teachers' personal and professional development, it is a primary factor in the qualitative improvement of education. In this way, it can make up for the shortcomings in the teachers' initial training or their potential decayed skills in the case where there is a long waiting period before they can enter the teaching profession - and reorganize the empirical knowledge they have accumulated during the exercise of their profession (Vergidis, 1991; Sakkoulis et al., 2017b).

From this point of view, in-service training constitutes a process which is politically and ideologically charged and the choices regarding content and its implementation reflect the hierarchy of the social and political powers within its field. The practices applied and the approaches that are followed within the field of in-service training, contain views on education and the teacher and echo beliefs on the type of learning that is preferred, and on the professional role and work of the teachers (Katsarou \& Dedouli, 2008).

In-service training may be perceived of as an imposition of a structural nature within the framework of the transmission of the official pedagogic discourse (Note 1), which maintains and strengthens established pedagogical modalities, expressing the macro-level (Bernstein, 1989; 2003).

Moreover, the official pedagogical discourse, since there is a primary contextualization in the initial framework of its production - where new ideas and specialised discourses are selectively created, developed, modified and changed - is repositioned in the field of recontextualization, whose chief mission is the formation of the "what" and the "how" of the pedagogical discourse (Bernstein, 1989 \& 2003). In-service training, as a channel for the diffusion of the recontextualised discourse to the teachers, defines the legitimate standards of identity, conscience and action of the subjects within each time-space framework, while it may promote alternatives to the traditional identities or strengthen and consolidate the already existing ones (Sarakinioti \& Tsatsaroni, 2010). More precisely, 
the official pedagogical discourse, as it is recontextualised within the field of in-service training, claims that it transforms knowledge into classroom talk and defines the pedagogical practices that are applied, shaping the pedagogical identities of the subjects (Barrett, 2009).

Yeo (1997), referring to teachers' initial education and training, emphasizes that these constitute preparation for the reading of the educational reality that they will experience during the exercise of their profession. Should the education and training be inadequate, this may potentially lead to distortions and the inability to deal with differentiated or difficult school contexts. The question derived from the above of whether activities, such as in-service training, can make up for the inadequacies in question. Hoadley (2006) mentions teachers whose "voice" is inadequately specialised for the job of transmitting school knowledge and highlights the impossibility for in-service training to cover the teachers' inadequacies.

Yoon et al. (2007) claim that the teachers' professional development is important for the improvement of teaching and school success, through the examination of hundreds of relevant studies. They conclude that most of in-service training programmes are one-day "laboratories", which offer superficial, unconnected, limited and non-cumulative knowledge. In addition, they note that the programmes in question do not provide a coherent structure and constitute a hodgepodge of official and unofficial opportunities, compulsory or optional, programmed or not.

From the aforementioned it can be concluded that a significant number of in-service activities of various forms, which shape a programme which is haphazard, unconnected and unpredictable in terms of content, are directed at teachers. In addition, it has been noted that interaction with colleagues in the workplace, occasional discussions and the everyday "friction" in the school classroom, shape the "mosaic" of an additional, light in-service training process, which specialists very possibly with limited knowledge of the field are frequently called on to handle (Wilson \& Berne, 1999). Consequently, the demand for the teachers' professional development goes hand in hand with the need for the systematic investigation of their learning.

In Greece in recent decades, the dialogue on teachers' in-service training, its content and its form has been widely developed (Lamnias, 2001; Kapsalis \& Rambidis, 2006; Matthaiou, 2008; Papanaoum, 2008; Vergidis, 1993a; 1993b; 1995; 2012). Despite this, we note that the concern regarding the contribution of in-service training to the formation of the teachers' individual theory of education is limited. This fact reveals the need for this aspect to be highlighted in the dialogue in progress.

In addition, we should mention that in-service training in Greece was essentially institutionalised after 1977, within the framework of the urban modernisation of the state. At this time, the first training bodies were created that were directed at wider groups of teachers. From the end of the 19th century until 1977 the institutionalised forms of training had had limited impact and a specific target. They mainly addressed teachers who intended to become educational executives (Vergidis, 2012).

The founding of In-service Training Schools after 1977, in the larger urban centres of the country, and the parallel operation of the Marasleio Teaching School (Note 2) led to the creation of a dual network of in-service training: The In-service Training Schools, which were directed at an increased number of teachers who would be returning to the classroom, and the Marasleio Teaching School, which was directed at a limited number of teachers who intended to become education executives.

In 1985 the operation of the Regional In-Service Training Centres (RTC) was introduced, and they began to operate from 1992. The RTC, initially, offered long-term in-service training programs, for a limited number of teachers. Gradually, the number of programmes on offer increased and they were, mainly, short-term programmes of an optional nature (Kapsalis \& Rambidis, 2006).

After 1995, when the European Union became more actively involved in national educational policy-making, a rapid increase as much in the in-service training programmes being implemented, as in the bodies involved in their implementation, was observed (Sakkoulis et al., 2017a). The Organization for the In-service Training of Teachers (OITT) was added to the existing public in-service training bodies, while at the same time many bodies (of a public and private nature) developed significant in-service training action (Sakkoulis et al., 2017a).

In recent years, Greece has begun to investigate the professional needs of teachers. Over the last decades, research has been carried out on the educational needs of teachers, both by official bodies and by independent researchers. The aforementioned studies record a series of educational needs of teachers, although most of the times they are limited mainly to the explicit preferences and the wishes (desires) of the teachers (Vergidis, 2012).

In 2011, the Institute for Educational Policy, which incorporated all the Ministry of Education in-service training bodies, was established. After a period of readjustment, the new structures began to implement in-service training policy-making. 
Finally, it is worth mentioning that beyond the in-service training processes, a significant portion of teachers in recent decades in Greece, participates in self-educational actions, which vary in terms of form and content (Sakkoulis et al., 2017a).

When it comes to the area of Patras, the planning of in-service training is done by the central government. The regional authorities provide in-service training that implements the central political choice. Regional directors or school managers may develop relevant actions that are individual and fragmentary. At the local level, we have training activities mainly from School Counselors, but they are usually not differentiated from the central government approach.

The aim of this paper, once we have examined the prevailing forms of in-service training of primary school teachers in the greek educational field, and highlighted the content of the recontextualised pedagogical discourse that these promote, is to examine the contribution of the in-service training of teachers to the formation of an individual theory of education.

To start with, we present, briefly, the concepts from the theory of B. Bernstein that we used in the sociological analysis of our data. This is followed by the setting out of the research questions and the methodology that we adopted. Then the research data are presented and analysed. The discussion and the presentation of the conclusion complete the paper.

\section{Theoretical Framework}

In our paper, we used the theory of B. Bernstein for the sociological approach and analysis of data. We used this theoretical framework because it is a cooperative theoretical construction that provides tools for interpreting social impacts on a micro-, meso- and macro- level (Bernstein, 1989; Lamnias \& Tsatsaroni, 1998). The concepts from this theory that we used in our analysis are the code, recontextualization, and recognition and realization rules.

The code, a central concept in B. Bernstein's theory is defined as a regulative principle, tacitly acquired, which selects and unifies the appropriate meanings, the forms of their realization, as well as the contexts in which they emerge (Bernstein, 1989; 2003). The codes are culturally determined and class regulatory mechanisms which place the subjects in relation to the dominant and dominated forms of communication and the relationships between them (Bernstein, 2003). Within the framework of B. Bernstein's theoretical schema, in-service training is approached as a process of socialization in the dominant pedagogical code. During the process of in-service training, the teachers are called on to internalize the interpretative methods of the particular code which will become ineffable guidelines for the regulation and coordination of their behaviour (Bernstein, 1989). From this point of view the processes compose or re-compose, as appropriate, the discrete elements of the individual theory of education.

With the concept of recontextualization B. Bernstein describes and interprets the process for the choice and transmission of knowledge from the field of its production to the fields of its transmission, to the spaces of formal, non-formal and informal education (Bernstein, 1989; Moore, 2004). The recontextualization process is substantial and is not a process of simplification for teaching purposes. There is a "special relationship" between knowledge and the individuals involved, the space and the time, the context and the accomplishments of the individuals within it, which is regulated and determined by the rules of the pedagogical mechanism (Young, 2003). In-service training takes part in this process transferring texts or practices from the primary context of the production of knowledge to the secondary context of its reproduction (Bernstein, 1989; 2003). It is composed, in other words, for "pedagogical purposes" and aims to provide teachers, in an economically viable and easily assimilated form, with the knowledge produced in the respective scientific fields (Solomon, 1994). As a process for the acquisition of particular orientations by the subjects involved, and for socialization, in-service training of teachers contributes to the acquisition of the rules of the pedagogical device, which concern the recognition rules and the rules of passive and active realization.

The recognition rules provide teachers with the opportunity to distinguish between the particular elements that characterize a school context and regulate the relevant meanings (Bernstein, $1989 \& 2000$ ). The teachers that have acquired the recognition rules are able to distinguish the elements that characterize the context in which they implement their pedagogical practices, and differentiate it from similar contexts (Morais, Neves, \& Afonso, 2005; Morais \& Neves, 2006).

The realization rules determine the accepted (or appropriate) processes for each context (Bernstein, 2000). The realization rules are divided into rules of passive and active realization. The acquisition of the rules of passive realization provides the teachers with the opportunity to choose the appropriate concepts and rationalizations in order to plan their pedagogical practices, while the possession of the rules of active realization, enables them to 
produce the texts that are required for the application of particular pedagogical practices in the classroom (Morais et al., 2005; Morais \& Neves, 2006). From this point of view, in-service training, within the context of life-long learning and the teachers' professional development, can contribute to their cognitive formation and help them in the better handling of the especially demanding school context.

\section{Methodology}

The questions that concerned us in the present research were:

a) What forms does the in-service training of primary school teachers take and what are the contents of the official pedagogical discourse that they promote?

b) Does the in-service training of primary school teachers influence the "individual theory of education" that they adopt?

For the selection of our sample, we applied the method of availability sampling (Kyriazi, 2011; Robson, 2010; Cohen et al., 2008). More precisely, we interviewed 11 teachers (4 men and 7 women) working in 7 Primary Schools in Patras (an urban area with a differentiated social composition). We note that the sample is not representative and the generalization of its results in the wider population is not feasible. In the context of qualitative research, the classical concept of generalization is redefined and replaced with the concept of compatibility (Cohen et al., 2008; Kyriazi, 2011). Prior to the interviews, the participants completed a questionnaire from which we drew their demographic details and information on their experience of in-service training. In terms of their origin, our research subjects came mainly from agricultural or lower middle-class backgrounds. They had between 8 and 32 years of experience in education and significant experience of in-service training on programmes of mid and short-term duration, organised by bodies overseen by the Ministry of Education. In addition, some of the participants stated that they had followed informal learning programmes, self-education actions and had participated in teachers' networks. The in-service training programmes they had participated in referred primarily to issues of teaching methodology, classroom management, the new technologies (ICT) as well as learning difficulties.

The research tool used to carry out the research was the semi-structured interview, which allowed us to focus on the multifaceted process of in-service training and study and highlight the views of the research subjects, from their "point of view" (Cohen et al., 2008).

The interviews were conducted in the research subjects' work place, at a pre-arranged time and since prior to each interview we had informed them concerning the objectives of the research and requested permission to use a tape recorder. The interviews were carried out over a period of five months (January - May 2014) and each interview lasted about one hour. We transcribed the interviews and carried out qualitative content analysis of the data that we gathered (Mason, 2003; Robson, 2010; Creswell, 2011). In addition, based on the objective of our research, as well as on its theoretical background, we continued to the categorization of our data, using the theme as our recording unit (Vamvoukas, 2000; Kyriazi, 2011). In terms of the degree of reduction, during the categorization of the recording units, we chose to remain with the obvious content of the text, in other words, the units that had a natural presence in the text (Robson, 2010; Kyriazi, 2011). We introduced two conceptual categories and one sub-category, through which the presentation, analysis and discussion of our findings were realised. The conceptual categories - and the particular sub-category - which were formed are the following:

1) The modalities in the recontextualized discourse during the in-service training process

1.1) The dominant reconceptualised texts in the field of in-service training

2) The cumulative accumulation of elements of the individual theory of education

\section{Presentation and Analysis of Data}

\subsection{The Modalities in the Recontextualised Discourse during the In-service Training Process}

The modalities in in-service training which appear in our research data are characterized by their limited breadth and the absence of alternative forms. The prevailing form of in-service training, as it has been highlighted in previous research in Greece (Vergidis et al., 2011a), is the lecture. Secondly, life-experience seminars and sample lessons are mentioned.

The lecture, as an in-service training technique, dominates in the discourse of all the teachers who took part in the research. The excerpts from the answers they gave us are indicative:

".... just about all the seminars that take place in Greece are organised in the same way. Lecture accompanied by Power Point. We read and listen to the same stuff simultaneously". (Teacher 6/T6). 
"At the seminars, always, one person talks, and the people simply listen." (T3).

As we have already mentioned, in the material we collected, there were references to experiential seminars. One teacher, placing emphasis on the forms of transmission that took place at the experiential seminar in which she participated, describes it as follows:

“...it could have been a work shop, it could have been a game, it could have been a role playing, it could have been anything within the educational process." (T5).

This means of in-service training seems to be considered more useful by the teachers in the sample, because it can be used in the classroom. These answers are characteristic:

"It was better at the experiential seminars, because you learn through doing." (T1).

"[The experiential seminars] function within the classroom, they give me the opportunity to break up the classroom and to reassemble in a pleasing way" (T2).

From the discourse of the teachers in the sample it appeared that the dominant forms of in-service training don't satisfy them as they believe that they don't correspond to their needs. They are often obliged to resort to self-education actions or to seek help in training seminars, often paying the corresponding price. Regarding this, they mentioned the following to us:

"I need help to manage. I read, and I attend seminars. Indeed, I often pay for them.” (T4).

"In my professional career, it was my self-education that was the most important, my own search!” (T3)

From this it is apparent that the prevailing form of training does not provide the teachers with realization rules. It doesn't arm them with concepts and practices that will allow them to advance to successful realizations in the communicative context of the school classroom (Bernstein, 2000). This shortcoming makes the planning and implementation of the process within the school context difficult and undermines daily school routine. The disappointment of the teachers in the sample was expressed in their discourse. The answers that follow are characteristic:

“[in-service training] could take place in a school classroom, but it’s far removed from the school!" (T3)

"At the seminars, the decision makers don't seem to be interested in what really happens in the classroom. I often get the feeling that they are more interested in their papers than in what the teacher needs" (T11)

The form as much as the content of the in-service training are distinguished by limited breadth, an element that undermines the development of a rich variety of recognition and realization data. One teacher characteristically mentioned that:

“In-service training wasn't what us teachers actually asked for. They just bandy around theories that had no relevance in the classroom" (T9)

The suggestion that emerges for the planning and organization of in-service training actions at the level of school unit, with the direct involvement of the interested teachers in the whole process, is interesting. A teacher from the sample indicatively suggests:

"It would be good if focal points for in-service training were created by the teachers themselves, on issues of common interest, within each school unit...It is very simple and doesn't cost anything. It could take place in every school and it would be the responsibility of the teachers" (T11)

Opinions like those mentioned highlight the seeds of doubt cast on the dominant pedagogical code and the creeping claim to merged codes, causing the first shifts in the collection codes which are dominant in the greek educational system (Bernstein, 1989; Lamnias \& Tsatsaroni, 1998; Varnava-Skoura \& Vergidis, 2011).

\subsection{The Dominant Recontextualised Texts in the Field of In-service Training}

Focusing on the contents of the in-service training seminars in which the teachers in our sample participated, we can see that these chiefly refer to:

- Recontextualised knowledge of the subjects taught in school

- Teaching of subjects

- The identification and handling of learning difficulties

- Pupil evaluation

- Classroom management and 
- The recontextualised knowledge of the sciences involved in education

The subjects which most seminars refer to are Modern Greek Language, Mathematics and the Natural Sciences. Two teachers mentioned characteristically:

"In the seminars, they just give us a general picture of all the subjects!" (T2)

"They focus mainly on the subjects of language, the Natural Sciences, Mathematics" (T11)

Although, as we have already mentioned, the dominant form and the contents of in-service training are distinguished by their limited range and the fact that they don't support the development of data of recognition and realization, on some issues the participants in the research highlighted elements of recognition rules.

More precisely, the diagnosis and handling of specialized learning difficulties constitutes the object of many seminars, in which the teachers of our sample participated. One teacher stated:

"I picked up things regarding children with special learning needs. I better understood those children" (T2)

We had similar comments on the topic of classroom management and the handling of delinquent behavior which some pupils develop. This type of seminar often, as a teacher confirmed, refers to the intra-unit relationships and their management:

"The content of the in-service training programs wasn't always purely pedagogical, it could have been relationships, communication within the team." (T11)

As far as the recontextualised knowledge of the sciences involved in the educational process (Sociology, Psychology, Pedagogy etc.) is concerned, the answers of the teachers in the sample mention Psychology and Teaching skills. Two teachers told us:

"They were chiefly pedagogical issues. The teaching of certain subjects...there were also taught psychology" (T8)

“They mentioned Psychology. The pupils' behavior." (T4)

Finally, the spread of ICT in the space of education in previous decades, as was to be expected, influenced the content of in-service training, as well as the teachers' individual theory of education. The acquisition of skills in the use of material means that are related to the new technologies constituted the object of many large, in terms of duration, seminars. The change in the material means used in teaching causes, unavoidably, modification too of the educational context. Established spatial provisions and interpersonal relationships change and new ones are introduced. Consequently, elements of the individual theory of education are re-set out and enriched. It is stated indicatively:

"Contact with the computer gave me great fluency. It broke down some of the boring and monotonous things that I traditionally had." (T2)

The comments of the teachers on the contents of the in-service training confirmed the inadequate provision of recognition and realization rules. The statements of the teachers often referred to a mismatch between the contents and the problems they face in the classroom. They also mention the inadequate target setting as well as the inconsistency of the contents of the in-service training (Bernstein, 2000). The excerpt that follows is characteristic:

"I always got the feeling that those who do the in-service training are out of touch with the world of the classroom. We have to find our own way. No in-service training can teach us that" (T5)

\subsection{The Accumulation of Elements of the Individual Theories of Education}

The individual (or micro-collective) theory of education (Note 3), a "cognitive nebula of educational theory and sociocultural views", according to Solomon (1994), is formed accumulatively through the dynamic interaction of a series of factors:

- During the teachers' time at school as pupils,

- During their professional education,

- During the exercise of their profession and the consequent accumulation of professional experience,

- Through the mechanism of the writing and spreading of educational ideas and practices,

- From the culturally specific context of the family and community and

- $\quad$ From the historically specific sociocultural processes.

There is often asymmetry or a mismatch between the principles of each teacher's individual theory of education 
and the principles that govern the school context, within which he is called on to act. In this case, a "space" for local - final recontextualization of the official pedagogical discourse is formed in the local school context (Solomon, 1994).

The teachers who participated in our research invoke the aforementioned factors, although the contribution of each particular element in the formation of the individual theory of education appears to be differentiated. For the purposes of our research, we separated the biographies of the teachers into two periods. These were the period prior to the exercise of their profession (pre-professional biography) and the period after they began to practice their profession (professional biography). We included the context of family upbringing, the surrounding community, experience as a pupil, and initial professional education in the first period, while the accumulated professional experience, contact with pedagogical discourse (written or spoken form) and in-service training were included in the second period. It is obvious that historically determined sociocultural processes run throughout the biographies of the subjects.

For the period that precedes the exercise of their profession, from their childhood until the completion of their initial professional education (pre-professional biography), we came across isolated references to experiences and knowledge in the contexts of the family or the wider community. Being from the agricultural or lower middle class the majority of questioned teachers didn't make mention of specific influences. The following testimonies from teachers are characteristic:

"I come from a farming family and since I experienced exclusion as a small child, I believed that what was important is to fight in our life so that inequalities are not created, to take the edge off them and to make them disappear." (T11).

Another teacher adds:

“...we are burdened by our farming past. [laughter] I always had to try on my own, I didn't get any help at home... This played a role for me in approaching and understanding the children, when I know that at home they are working alone." (T3)

The experience of the research subjects as pupils in primary and secondary education and the teaching models they encountered are often referred to as instances of either mimicking or avoidance. One teacher describes this:

“As a pupil, I didn't have great experiences [laughter]. We grew up in a very teacher-centred, strict, non-democratic, which severely punished using corporal punishment. All this distanced me and I said that I want to do something different!" (T8)

Teacher 6 also mentions similar experiences:

"What I didn't like was the distanced and cold teacher - pupil relationship. I tried and I'm still trying to change it. For me not to be the teacher - power who orders and the children obey!" (T6)

A special mention was made of teachers who were the "significant others" for the research subjects. The following testimony is characteristic:

"I got positive things from my teachers, they made me look on this profession as a standard and I chose it. They were significant others, for me..." (T11)

"There are teachers from Junior and Senior High School who played a decisive role" (T3)

The research subjects' views on the initial training they had in the Pedagogical Academies or the University Teaching Departments are interesting. Those who mentioned this believe that they were not capable of supporting the future demands of their job in the classroom. So, one teacher mentions:

"In the Academy, I didn't have any kind of way, beyond a couple of professors who we had for art and who were shining examples of teachers, I can't remember anyone else..." (T5)

A similar position is expressed by another teacher:

"What we learnt at the University, compared with what we face in the classroom, are entirely different things!" (T10)

As another teacher from the sample explained to us, between the content of the studies and the school, there is a "chasm". She states characteristically:

"At the University, we had seen little of School. I had no idea, no picture of what school was like. The School I left in 1980 with the School I found in 1993 in Kalavrita bore no relationship with each other!" (T7)

These views testify to the fact that the initial studies, as an element of the pedagogical context of 
recontextualization, are lacking in terms of the adequate re-shaping of pedagogical discourse and the effective recognition of its field of application (Bernstein, 1989). The incomplete recontextualization of the pedagogical discourse during the candidate teachers' initial studies is underlined by Yeo (1997), when he mentions the inadequate preparation of teachers to meet the challenge of "difficult" school units.

However, while the pre-professional biography, according to the views of the teachers in our sample, had a possibly reduced - as a product of the time - influence on the formation of their individual theory of education, it seems that their entry into the profession and the subsequent processes contributed decisively.

The individual theory of education is gradually enriched and renewed by the accumulated professional experience during the exercise of the profession, the interaction with fellow teachers, with education executives, as well as with the pupils.

Hence accumulated experience is an important parameter. The individual theory of education is enriched and renewed with the passage of time. As a teacher in the sample remarked:

"With each year that passes you feel that you have acquired certain things. Some things that were difficult for you, you now handle with greater ease. Experience acts additively". (T8)

An element that emerges in all the interviews with the research subjects is the interaction with their colleagues in the school context. All the teachers in our sample mentioned the impact that colleagues have on them. The following views are indicative:

"I owe my colleagues a lot. I have been lucky to work with worthy people and for there to be interaction. We exchanged things, we learnt. Some research you did, something you read, all those things moved me forward." (T5)

"Some older teachers who came into my classroom helped me with the way they spoke to me and they told me how to handle it and I did it and I saw that it worked." (T4)

The influence of the group of colleagues has been investigated in the past in Greece (Gotovos \& Mavrogiorgos, 1984 ) and it has been claimed that it often functions as a mechanism of assimilation and conformity. One teacher states characteristically:

“...the teacher is assimilated into the system very easily. You can't have continual workplace friction with your colleagues. You reign yourself in again and again and then you easily become isolated and you can't do things that you could." (T11)

Wilson \& Berne (1999) note, similarly, the importance of interaction with colleagues and the chance discussions in the workplace. In addition, they emphasize the importance of everyday friction in the classroom and the intervention of the "specialists" (like the School Advisors), who often have inadequate knowledge of the field. The following remarks are relevant:

"I too change through the children. Every year I get to know the children better, I discover things about my job." (T2)

"The School Advisor only helped me in the first years in the small schools. In the big Schools that I have worked In the Advisor hasn't happened to visit so that we can see some things together." (T2)

Bernstein (1989 \& 2000) highlights the role played by the later recontextualization processes which occur in the field of the reproduction of pedagogical discourse, in the school context. In other words, the local context, which contains factors like those mentioned above, imposes a new, final re-positioning of texts. In-service training has a central position in the recontextualization of pedagogical discourse. It functions, chiefly, in the official field of recontextualization - which is often of a compulsory nature - as well as in the pedagogical field of recontextualization and contains elements strengthening and establishing the existing theory of education the teachers bring or elements of its deconstruction and the re-composition of new cognitive schemata (Lamnias \& Tsatsaroni, 1998 \& 1999).

As a process of the recontextualization of pedagogical knowledge, in-service training has a differentiated impact on the construction of the individual "micro-collective" theory of education the teachers bring with them. The differentiation is related to the modalities and the contents that they receive, as well, as was mentioned previously, as with the teacher accepters (Bernstein, 2000).

The research subjects that took part in our research, while they mentioned that there were elements of influence from the training seminars they participated in, are differentiated in terms of the degree of influence. The impact, as a teacher in our sample mentions characteristically, while existent, is hard to discern: 
"It is not easy for me to tell you that from this in-service training I got this piece" (T1)

The weak contribution of the in-service training seminars that our subjects participated in becomes obvious from their narratives. They state characteristically:

“...I did a seminar at RIC. Not that I can remember anything!" (T7)

For some teachers in the sample, the in-service training seminars they took part in did not provide new knowledge and constituted merely a revision of their initial studies. From this point of view a teacher in the sample clearly states:

"...it was simply a revision of what we had done at University. It provided some, a few, new elements" (T6)

Although Although the in-service training seminars in which the teachers in our sample participated didn't meet their expectations, it seems that their teaching skills were influenced by them. Two teachers mention:

"The training in Language, [and] computers changed the way I work. [...] I was influenced, I changed my methods of evaluation" (T2)

"...they helped me in the management of the behavior of certain of my pupils more than anything" (T4)

Of interest are the comments of the research subjects on optional in-service training programmes or their participation in teacher networks. The positive effect these training programmes have is clear in their discourse. The following testimony is characteristic:

"I went to a seminar that a University professor had organised! I was impressed, and he has opened at new horizons for me, I saw teaching from a new point of view. At that time I understood that something else was happening. I owe him that" (T5)

Furthermore, the reference a teacher made to a teachers' network, of an optional nature, aimed at training in innovative pedagogical practices is revealing:

"Through the network we experienced things that we had never imagined. And we managed to bring them into the classroom." (T8)

The attempt at self-education and a personal search for recontextualised knowledge is also interesting. The diffusion of pedagogical discourse through the mechanism of writing and the transmission of educational ideas and standards (Solomon, 1994), is found in the material we collected when the teachers refer to a personal search for theoretical material which enriched their individual theory of education. With regards to this they told us:

"What I learnt, I learnt by studying alone. I always used to study pedagogical books too and some books that existed then, that even the advisors didn't know about." (T5)

"From one point and on I cultivated it by myself, I continued like that, with my own education, with my own cultivation." (T9)

As Morais et al. (2005) claim the adoption of practices and positions that are promoted through processes of professional development falls apart when there is a mismatch between the programmes of professional development and the pedagogical practices that the teachers are called on to implement in the classroom. In-service training may bring about re-shaping in the individual theory of education; strengthen the teachers' professional development and their ability to guide their pupils to a higher level of scientific development. However, for this to happen, the teachers are required to have a good knowledge of the cognitive teaching subjects, assimilation of scientific knowledge regarding education and the child, as well as the application of this knowledge in the school classroom. Professional development comes about through investigation and trial application, in an environment of support and feedback. It is important that the processes of professional development have a clear theoretical base, consistent and firm conceptual frameworks, and to take into consideration the sociological dimension of education. Finally, for the acquisition of specific pedagogical practices, and their successful application, isomorphism between the modalities of in-service training and the modalities of the pedagogical practices in school is an essential prerequisite. It is however a fact that most in-service training models, on an international level, don't apply it. They apply a "closed pedagogy" although they talk about "open pedagogy".

Our research data reveal that in-service training is lacking and cannot overcome the powerful influence of stereotypes, like the copying of standards and accumulated experience, in the process of the formation of the individual theory of education. The partial penetration of the recontextualised texts of in-service training is to be found as much in the inadequate acquisition of the recognition rules as in the realization rules (see too Bernstein, 1989; Bernstein, 2000). The teachers in our sample, as we observed in their previous remarks, do not shape, during the training, the means for the distinction and recognition of special/distinct elements of the context, as these are 
differentiated in the context of the Primary School (Bernstein, 2000). In addition, and when this is accomplished, they are often not able to choose the concepts or practices that are appropriate for the context or to create suitable "texts" (Bernstein, 1989). We believe that the probable interpretation of this aforementioned weakness is to be found in the content of the recontextualised texts that dominate in the in-service training, as well as in the modalities that this receives.

\section{Discussion-Conclusions}

In this paper, our aim was to highlight the prevailing forms of in-service training of primary education teachers, and the content of the recontextualised discourse that these promote. In addition, we investigated the degree of influence that in-service training has on the formation of the individual theory of education.

According to our research data, in-service training presents a limited range of forms of realization. The prevailing form of training is the lecture, a finding which is in agreement with previous research (Vergidis et al., 2011a; Vergidis et al., 2011b). Secondly, experiential seminars, sample lessons and self-education actions were mentioned. The latter are clearly smaller in number to the dominant form and are characterised by chance appearance. The prevailing form does not offer the teachers elements capable (recognition and realization rules) of effective action within the context of the school classroom.

The mismatch between the dominant form of in-service training (lecture) and the pedagogical practices (team work models, projects) that constitute the demand of the dominant pedagogical code, as this is set out in the official pedagogical code in Greece, undermines the possibility of the isomorphism of training and pedagogical practice (Morais et al., 2005). In similar cases, we believe that in-service training ends up being ineffective since it doesn't provide the rules of active realization to produce the suitable texts (Bernstein, 2000).

The aforementioned are also supported by the positive acceptance that the alternative forms of training that were mentioned receive. The direct involvement of the teachers in the process and the opportunity to transfer the recommended alternative models to the context of the school classroom strengthen the process of in-service training and make it capable of intervening in the dynamic process of the formation of the individual theory of education. However, such an influence was only discerned in programmes of an optional nature, in the networks of teachers that use training actions and in the programmes that promote the use of ICT in the educational act.

Regarding the recontextualised texts that dominate in-service training, we noted that they chiefly refer to the contents and the teaching of the subjects, the diagnosis and handling of learning difficulties, classroom management, the acquisition of the use of supplementary teaching aids (mainly ICT) and the contents of the sciences involved in the pedagogical process (e.g. Psychology). The degree of influence of the aforementioned elements varies according to teacher.

In-service training, as a channel for the transfer of the recontextualised discourse to the teachers, contributes to the re-positioning of the specialised scientific discourses in the field of the reproduction of pedagogical discourse, within an educational level (Bernstein, 1989; Moore, 2004). According to the data we gathered, the recontextualised discourse that is diffused through training to the teaching staff in our sample focuses on the contents of teaching objects and "techniques" for the carrying out of the educational act, on the "what" and the "how" of the educational process. As Solomon mentions (1994), the actual context of the production of knowledge is suppressed, and a selected series of data and certainties is recommended, a set of rules for the use of certain scientific data. The teachers are limited to receivers of chosen information and are estranged from the actual practices for the production of knowledge.

As far as the individual theory of education is concerned, the data we gathered in our research confirms a partial, gradually reducing, influence of the teachers' pre-professional biography on the process of the formation of the individual theory of education. The prevailing principle of formation for the teachers in our sample is the professional biography, as this is analysed in the accumulated professional experience during the exercise of their profession, in the interaction with their colleagues and the developing pedagogical relationship they develop in the field of the school classroom. In-service training, "trapped" in ineffective contents and forms, undermines the process of the formation of the individual theory of education. Its differentiated influence, functions supplementary in the maintenance and strengthening of the dominant pedagogical code, although in certain cases, possibly, it could also function as the beginning of its undermining and questioning (Bernstein, 1989). The increased degree of penetration and the dynamic that certain forms of in-service training demonstrate is something which requires further investigation and analysis. The particular references confirm that in-service training, under certain preconditions, can constitute a dynamic element in the composition and re-composition of the individual theory of education the teachers bear. 
We believe that the previous observations raise issues related to the design, form and contents of in-service training in our country. From this point of view, the unanimous rejection of the dominant model of the lecture, the demand for the involvement of those directly interested in design and implementation, the promotion of "good practices" can constitute elements for the enriching of the developing related dialogue.

\section{References}

Barrett, B. (2009). No Child Behind and the assault on the teachers' professional practices and identities. Teaching and Teacher Education, 25, 1018-1025. https://doi.org/ 10.1016/j.tate.2009.03.021.

Bernstein, B. (1989). Pedagogical codes and social control. Introduction, translation, notes I. Solomon. Athens: Alexandreia.

Bernstein, B. (2003). Class, Codes and Control (Volume IV). The Structuring of Pedagogic Discourse. London: Routledge.

Bernstein, B. (2000). Pedagogy, symbolic control and identity: Theory, research, Critique (Revised Edition). Lanham: Rowman \& Little field Publishers, Inc.

Bien, O., Merten, S., \& Schnotz, W. (2015). The Individual Theories of Teachers about Vocabulary Work with Mono- and Plurilingual Students in the German Language Classroom. In W. Schnotz, A. Kauertz, H. Ludwig, A. Müller, \& J. Pretsch (Eds.), Multidisciplinary Research on Teaching and Learning (pp. 129-145). Springer.

Bouzakis, S., Tzikas, H., \& Anthopoulos, K. (2000). In-service training and re-training of teachers and pre-school teachers in the Modern Greek state. Athens: Gutenberg.

Cohen, L., Manion, L., \& Morrison, K. (2008). Methodology of educational research. Athens: Metaixmio.

Creswell, J. (2011). Research in Education. Design, Conduct and Evaluation of Quantitative and qualitative Research. Athens: ion/Ellin Publications.

Gotovos, T., \& Mavrogiorgos, G. (1984). The professional socialization of the newly appointed teacher: From the desk to the teacher's table. In T. Gotovos, G. Mavrogiorgos, \& P. Papakonstadinou (Eds.), Critical Pedagogy and educational act (pp. 105-116). Giannena: Contemporary Education.

Hoadley, U. (2006). Analyzing pedagogy: The problem of framing. Journal of Education, 40, 15-34.

Kapsalis, A., \& Rambidis, K. (2006). Initial in-service teacher training: Internal evaluation of an endeavour. Education \& Science, 1(3), 257-273.

Katsarou, E., \& Dedoula, M. (2008). In-service training and evaluation in the space of education. Athens: Pedagogical Institute.

Kyriazi, N. (2011). Sociological research: Critical Evaluation of Methods and Techniques. Athens: Pedio

Lamnias, K. (2001). In-service teacher training and school practice: Pupil evaluation. In K. P. Haris, N. B. Petroulakis, \& S. Nikodimos (Eds.), Continuing Education and Lifelong Learning: International Experience and Greek Prospect, Proceedings from the 8th International Conference of the Pedagogical Society of Greece (pp. 434-447). Athens: Atrapos.

Lamnias, K., \& Tsatsaroni, A. (1998). The processes of recontextualization in the course of the production of school knowledge. Prerequisites for change in school practices (part 1). Contemporary Education, 102, 73-80.

Lamnias, K., \& Tsatsaroni, A. (1999). The processes of recontextualization in the course of the production of school knowledge. Prerequisites for change in school practices (part 2). Contemporary Education, 103, 70-77.

Mason, J. (2003). The conduct of qualitative research. Athens: Ellinika Grammata.

Matthaiou, D. (2008). From in-service training to continued professional development of the teacher - New priorities and approaches. Introduction to the 20th Conference of the Pedagogical Institute on the topic "In-service training of Education Executives: Actions - Results - Prospects", 19-20 June 2008. Volos. Retrieved from http://users.uoa.gr/-dmatth/02_conferences.html

Moore, R. (2004). Education and society: Issues and explanations in the Sociology of Education. Cambridge: Policy Press.

Morais, A., \& Neves, I. (2006) Teachers as creators of social contexts for scientific learning. In R. Moore, M. 
Arnot, J. Beck, \& H. Daniels (Eds.), Knowledge, Power and Educational Reform: Applying the sociology of Basil Bernstein (pp. 146-163). Abingdon: Routledge

Morais, A., Neves, I., \& Afonso, M. (2005). Teacher training processes and teachers' competence. A sociological study in the primary school. Teaching and Teacher Education, 21, 415-437 https://doi.org/10.1016/jtate.2005.01.010

Papanaoum, Z. (2008). For a better school: The role of in-service training of teachers. In Introductions from the two-day workshop "Education and quality in the greek school" (pp. 54-61). Athens: Pedagogical Institute

Robson, C. (2010). Research of the real world. Athens: Gutenberg

Sakkoulis, D., Asimaki, A., \& Vergidis, D (2017b). In-service training of early school age teachers and its contribution to the shaping of the individual theory of education. In A. Dimitriou, H. Sakonidis, E. Malkopoulou, H. Boutziloudi, \& A. E. Tebridou (Eds.), Proceedings from the 10th O.M.E.P. - D.U.TH Conference. Educating citizens for a sustainable future. The role of pre-school and early school age education (vol. A, pp. 304-311). Alexandroupoli.

Sakkoulis, D., Asimaki, A., \& Vergidis, D. (2017a). In-service training of teachers: Matters of definition and typology. Greek experience and international trends. Educational Cycle, 5(1), 104-126

Sarakinioti, A., \& Tsatsaroni, A. (2010). Study Programmes and pedagogical identities in the Education of Greek Teachers: An analysis model. In B. Koulaidis, \& A. Tsatsaroni (Eds.), Pedagogical practices: research and educational policy (pp. 179-223). Athens: Metaixmio

Solomon, I. (1994). Educational action and social regulation of subjects: Knowledge, discipline and the field of the school. In I. Solomon, \& G. Kouzelis (Eds.), Discipline and knowledge (pp.113-144). Athens: S.S.H.S.

Sutherland, M. B. (1985). The place of theory of education in teacher education. British Journal of Educational Studies, 33, 222-234. https://doi.org/10.1080/00071005.1985.9973714

Varnava-Skoura, J., \& Vergidis, D. (2011). The unresolved step of an attempt to develop differentiated educational practices and the handling of school failure. In D. Vergidis, \& A. Yfanti (Eds.), Issues of educational policy. Theoretical starting points and educational programmes for the improvement of the School (pp. 117-146). Athens: Ypsilon/Biblia

Vergidis, D. (1991). Illiteracy and social growth. Patra: University of Patras.

Vergidis, D. (1993a). Neo-liberal educational policy and the in-service training of teachers (part 1). Contemporary Education, 69, 42-49.

Vergidis, D. (1993b). Neo-liberal educational policy and the in-service training of teachers (part 2). Contemporary Education, 70, 67-73.

Vergidis, D. (1995). From the In-service Training Schools to the Regional In-service Training Centres. A critical review of in-service teacher training. In A. Kazamias, \& M. Kassotakis (Eds.), Greek Education: prospects for reformation and modernization (pp. 477-494). Athens: Seirios.

Vergidis, D. (2012). The in-service training of teachers in Greece as a dimension of educational policy. Science and society, 29, 97-126.

Vergidis, D., Yfanti, A., Anagnou, B., Bathi, P., Valmas, Th., Vozaitis, G., et al. (2011b). The in-service training practices in the initial in-service training of teachers. In G. Bagakis (Ed.), Initial in-service training: Highlighting good practices, investigation of problems and detection of prospects (pp. 11-27). Athens: TTO

Vergidis, D., Yfanti, A., Anagnou, B., Bathi, P., Zisimopoulos, D., Markopoulou, M. et al. (2011a). External evaluation of the programme "Initial in-service training for newly appointed and recruited substitute teachers for the school year 2010-2011 ". Patra: University of Patras, Teacher Training Organization.

Wilson, S. M., \& Berne, J. (1999). Teacher learning and the acquisition of professional knowledge: An examination of research on contemporary professional development. In A. Iran-Nejad, \& P. D. Pearson (Eds.), Review of Research in Education (24, pp. 173-209). Washington, DC: American Educational Research Association. https://doi.org/10.2307/1167270

Yeo, F. (1997). Teacher Preparation and Inner-City Schools: Sustaining Educational Failure. The Urban Review, 29(2), 127-143. https://doi.org/10.1023/A:1024686607759

Yoon, K. S., Duncan, T., Lee, S. W.-Y., Scarloss, B., \& Shapley, K. (2007). Reviewing the Evidence on How Teacher Professional Development Affects Student Achievement. Issues \& Answers. REL 2007-No. 033. 


\section{Regional Educational Laboratory Southwest, \\ 62. $\quad$ Retrieved from} https://ies.ed.gov/ncee/edlabs/projects/project.asp?ProjectID=70

Young, M. (2003). Curriculum Studies and the Problem of Knowledge: updating the Enlightenment? Policy Futures in Education, 1(3), 553-564. https://doi.org/ 10.2304/pfie.2003.1.3.7

\section{Notes}

Note 1. The concept of pedagogical discourse in this paper is understood as "a rule which embeds two discourses; a discourse of skills of various kinds and their relations to each other, and a discourse of social order" (Bernstein, 2000, pp. 31-32).

Note 2. The Marasleio Teaching School for Primary Education was a school for the training of teachers, with a two-year study period, which was established in 1972. A corresponding in-service training structure operated under the supervision, successively, of the University of Athens (1922-1964), the Pedagogical Institute (1964-1967) and the Teaching School for Primary Education (1967-1972). It continued to operate until 2012, when its operation ceased. In the period of its operation, it underwent significant changes in terms of supervising body and content of studies, depending on the political changes that took place in Greece in the same period (Bouzakis et al., 2000).

Note 3. Relating to the individual theory of education of teachers see Sutherland (1985), Solomon (1994), Bien et al. (2015).

\section{Copyrights}

Copyright for this article is retained by the author(s), with first publication rights granted to the journal.

This is an open-access article distributed under the terms and conditions of the Creative Commons Attribution license (http://creativecommons.org/licenses/by/4.0/). 